\title{
Selective 5-HT7 receptor agonists LP 44 and LP 211 elicit an analgesic effect on formalin-induced orofacial pain in mice
}

\author{
Kadriye DEMiRKAYA 1 , Özlem Martı AKGÜN² , Buğra ŞENEL ${ }^{3}$, Zeynep ÖNCEL TORUN'1', Melik SEYREK ${ }^{4}$, Enza LACiviTA ${ }^{5}$, \\ Marcello LEOPOLDO ${ }^{5}$, Ahmet DOĞRUL ${ }^{4}$
}

1- Gulhane Medical Academy, Department of Restorative Dentistry and Endodontics, Ankara, Turkey.
2- Gulhane Medical Academy, Department of Pediatric Dentistry, Ankara, Turkey.
3- Gulhane Medical Academy, Department of Dentomaxillofacial Radiology, Ankara, Turkey.
4- Gulhane Medical Academy, Department of Pharmacology and Pain Research Centre, Ankara, Turkey.
5- Università degli studi di Bari Aldo Moro, Dipartimento di Farmacia - Scienze del Farmaco, Bari, Italy.

Corresponding address: Kadriye Demirkaya, DDS, PhD - Gulhane Medical Academy, Department of Restorative Dentistry and Endodontics - General Tevfik Saglam Cad. No: 1 - Ankara - TURKEY - Phone: +90 3123046033 - e-mail: kdemirkaya@gata.edu.tr

Submitted: December 14, 2015 - Modification: March 10, 2016 - Accepted: March 15, 2016

\section{ABSTRACT}

\begin{abstract}
The most recently identified serotonin (5-HT) receptor is the 5-HT7 receptor. The antinociceptive effects of a 5-HT7 receptor agonist have been shown in neuropathic and inflammatory animal models of pain. A recent study demonstrated the functional expression of 5-HT7 receptors in the substantia gelatinosa (SG) of the trigeminal subnucleus caudalis, which receives and processes orofacial nociceptive inputs. Objective: To investigate the antinociceptive effects of pharmacological activation of 5-HT7 receptors on orofacial pain in mice. Material and Methods: Nociception was evaluated by using an orofacial formalin test in male Balb-C mice. Selective 5-HT7 receptor agonists, LP 44 and LP 211 (1, 5, and $10 \mathrm{mg} / \mathrm{kg}$ ), were given intraperitoneally 30 min prior to a formalin injection. A bolus of 10 $\mu \mathrm{l}$ of $4 \%$ subcutaneous formalin was injected into the upper lip of mice and facial grooming behaviors were monitored. The behavioral responses consisted of two distinct periods, the early phase corresponding to acute pain (Phase I: 0-12 $\mathrm{min}$ ) and the late phase (Phase II: $12-30 \mathrm{~min})$. Results: LP 44 and LP $211(1,5$, and $10 \mathrm{mg} / \mathrm{kg}$ ) produced an analgesic effect with reductions in face rubbing time in both Phase I and Phase II of the formalin test. Conclusion: Our results suggest that 5-HT7 receptor agonists may be promising analgesic drugs in the treatment of orofacial pain.
\end{abstract}

Keywords: Formalin. Receptor agonists. Orofacial pain.

\section{NTRODUCTI ON}

Orofacial pain treatments remain an important consideration in dental care and patient management. Patients often evaluate a clinician's ability by their success or failure in pain control. Dental pain management requires a multifactorial approach that includes a combination of good treatment procedures and the use of appropriate analgesics ${ }^{12}$.

The majority of drugs used to manage pain in Dentistry are nonsteroidal anti-inflammatory drugs (NSAIDs) and opioid analgesics ${ }^{10}$. Opioid analgesics are controlled substances and have many serious adverse side effects such as drug abuse, nausea, and vomiting ${ }^{3}$. Thus, most acute dental pain can be managed with the proper NSAID. However, subacute and chronic dental pain present difficulties due to the problems associated with the long term use of NSAIDs, which may be associated with significant side effects including gastrointestinal and renal diseases ${ }^{17}$. Thus, it is necessary to discover new drugs and new target molecules to relieve severe dental pain.

It is well known that serotonin plays a crucial role in the regulation of pain via its interaction with 5-HT receptors ${ }^{2}$. Previous studies have reported roles for 5-HT1A, 5-HT2, and 5-HT3 receptors in 
pain regulation $9,14,16$. The 5 -HT7 receptor is the most recently identified $5-\mathrm{HT}$ receptor and a variety of studies have provided evidence that $5-\mathrm{HT} 7$ receptor agonists produce antinociceptive effects in a variety of inflammatory and neuropathic pain models. In a recent study, Yang, et al. ${ }^{20}$ (2014) indicate that 5-HT7 receptors are functionally expressed in a subpopulation of the substantia gelatinosa of the trigeminal subnucleus caudalis, which receives and processes orofacial nociceptive inputs. To our knowledge, no studies have evaluated the efficacy of $5-\mathrm{HT} 7$ receptor agonists on orofacial pain. In this study, we investigated the effects of selective 5-HT7 receptor agonists, LP 44 and LP 211, on orofacial pain using a formalin model in mice.

\section{MATERI AL AND METHODS}

\section{Selection of the experimental group}

Experiments were performed in the Drug Research and Development Laboratory of Pharmacology Department. Female Balb-C (25-32 g) mice were used. Mice were housed in a wellventilated room at $22 \pm 2^{\circ} \mathrm{C}$ under a $12 \mathrm{~h}$ light: $12 \mathrm{~h}$ dark cycle and with free access to food and water. The experimental group consisted of 6-8 mice. Nociception was evaluated by using orofacial formalin test. Each of the subjects were allowed to separately provide adaptation within 30 min in the observation room in which a $30 \times 30 \times 30 \mathrm{~cm}$ Plexiglas box was placed with mirrors with a 45 degree angle to see unobstructed views of the orofacial region. The protocol was approved by the Animal Care and Use Committee.

\section{Drugs}

Selective 5-HT7 receptor agonists, LP 44 and LP 211, were used for this study. While LP 44 was dissolved in distilled water, LP 211 was dissolved in 5\% dimethyl sulfoxide (DMSO). LP 44 and LP 211 $(1,5$, and $10 \mathrm{mg} / \mathrm{kg})$ were given intraperitoneally (i.p.) in a volume of $5 \mathrm{ml} / \mathrm{kg}, 30$ minutes prior to the formalin injection. Vehicle was given to the control groups.

\section{Orofacial formalin test and the assessment of antinociceptive effects \\ Orofacial nociception was evaluated using} formalin as previously described ${ }^{11}$. A bolus of $4 \%$ formalin $(10 \mu \mathrm{l})$ was subcutaneously injected into the upper lip of mice just lateral to the nose. The time of the paw strokes directed to the injection area, called face rubbing, was recorded over a 30-minute period, which was divided into 10 blocks of 3 min each, while the mice were in Plexiglas cages. In our study, cumulative data collected between 0 and 9 min post-formalin injection were grouped as phase 1 (0-9 $\mathrm{min})$, whereas phase 2 was composed of data collected between 12 and 30 min post-formalin injection (the late phase).

\section{Statistical analysis}

Data are expressed as means \pm standard error of the mean (SEM) for each group. GraphPad Prism 4 software (GraphPad Software, San Diego California, USA) was used for the statistical analyses. In the first stage, the time course effects of drug or vehicle treatment on face rubbing responses were evaluated by two-way repeated measure analysis of variance. Next, the averages of the period (0-9 min for Phase I and 12-30 min for Phase II) were calculated in each animals (bar graphs) and one way ANOVA were used to compare groups. A significant effect on the main factor(s) was taken as the criterion for progressing to post-hoc testing. The Bonferroni post-hoc test was used to compare the groups. Statistical significance was accepted as $\mathrm{p}<0.05$.

\section{RESULTS}

Consistent with previous studies, following the formalin injection, a typical biphasic time course with an early and short-lasting (9 min) first period of activity (Phase I) was observed. This was followed by a 3-minute quiescent period. Then, a second, prolonged (12-30 min) tonic phase (Phase II) was observed (Figure 1A). The mean of the total face rubbing times were $96.29 \pm 1.6$ seconds and $61.33 \pm 2.41$ seconds during Phase I (0-9 min) and Phase II (12-30 min), respectively (Figures $1 \mathrm{~B}$ and $1 \mathrm{C})$.

The two-way repeated measures of ANOVA analysis indicated that systemic administration of LP 44 had significant effect on face rubbing responses induced by formalin injection $\left(F_{3,392}=601.1\right.$, $\mathrm{P}<0.0001$ ) (Figure $1 \mathrm{~A}$ ). While $1 \mathrm{mg} / \mathrm{kg}$ was ineffective, LP 44 doses of 5 and $10 \mathrm{mg} / \mathrm{kg}$ profoundly reduced face rubbing times at 3 and $6 \mathrm{~min}$ in Phase I (Figure 1A). Similar to Phase I, LP 44 at doses of 5 and $10 \mathrm{mg} / \mathrm{kg}$ significantly inhibited formalininduced face rubbing responses at 15, 18, 21, and $24 \mathrm{~min}$ in Phase II (Figure 1A). The mean of the total face rubbing times in Phase I, after LP 44 injection at the doses of 5 and $10 \mathrm{mg} / \mathrm{kg}$, were significantly reduced to $45.5 \pm 1.08$ and $24.8 \pm 1.3$ $\mathrm{s}$ (both $\mathrm{p}<0.001$ ), respectively, in Phase $\mathrm{I}$, which were significantly different from control groups (Figure 1B). LP 44 at the doses of 5 and $10 \mathrm{mg} /$ $\mathrm{kg}$ also significantly reduced the total face rubbing times to $41 \pm 1.08$ and $7.3 \pm 0.7 \mathrm{~s}$ (both $\mathrm{p}<0.01$ ), respectively, in Phase II, when compared with the control group (Figure 1C).

Similar to LP 44, systemic administration of LP 211 had significant effect on formalin-induced face rubbing responses in Phase I and II of the formalin 
test $\left(F_{3,392}=213.77, P<0.0001\right)$ (Figure $\left.2 A\right)$. While LP 211 at a dose of $1 \mathrm{mg} / \mathrm{kg}$ did not alter formalininduced nociceptive face rubbing responses, LP 211 doses of 5 and $10 \mathrm{mg} / \mathrm{kg}$ significantly reduced face rubbing times at 3 and 6 min in Phase I (Figure 2A). The antinociceptive effects of LP 211 at the doses of 5 and $10 \mathrm{mg} / \mathrm{kg}$ were evident at 15, 18, 21, and

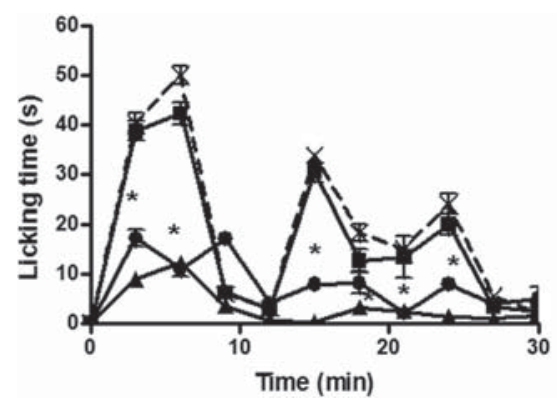

A

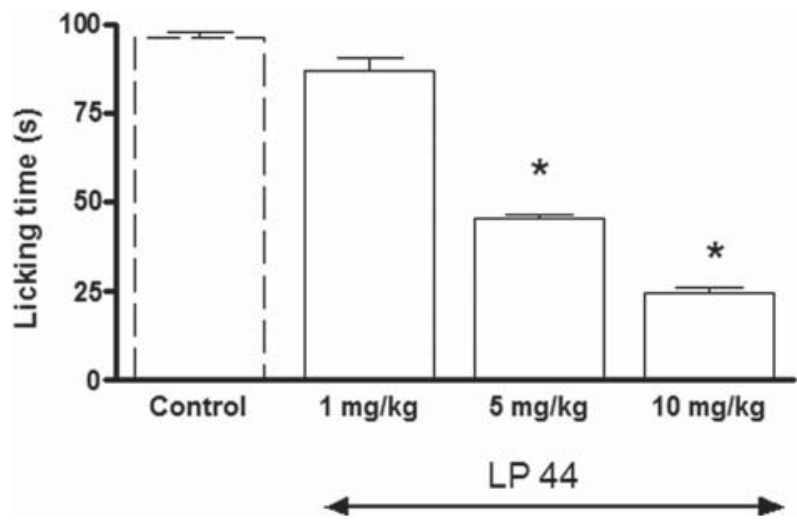

B

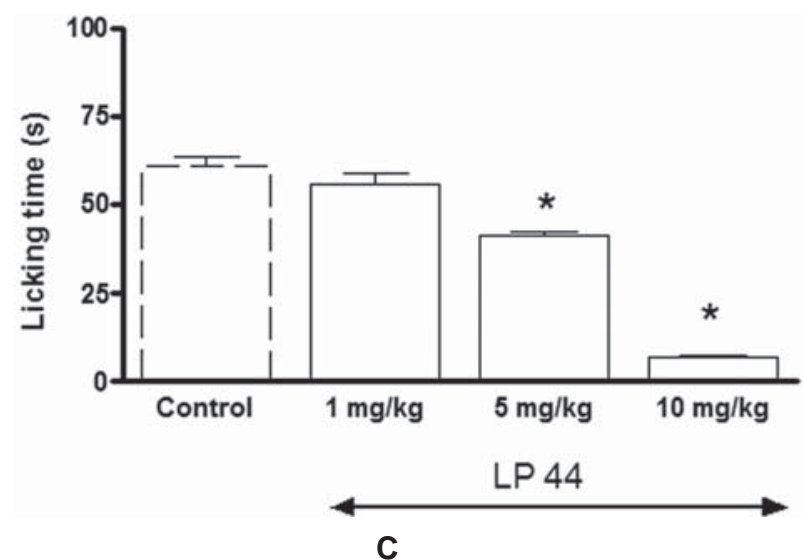

Figure 1- Time course of face rubbing activity induced by formalin injection into upper lip after systemic administration of LP 44, a selective 5-HT7 receptor agonist, or vehicle. Mice were pretreated with systemic administration of LP 44 (1, 5, and $10 \mathrm{mg} / \mathrm{kg}), 30 \mathrm{~min}$ prior to injection of $4 \%$ formalin $(10 \mu \mathrm{l})$ into upper lip (A). Bar graphs represent the mean cumulative face rubbing time in $\mathrm{S}$ at Phase I (0-9 min) (B) and Phase II (12-30 min) (C). ${ }^{*} P<0.05$, differences from control groups (Bonferroni post hoc test)
24 min in Phase II when compared with the vehicle group (Figure $2 \mathrm{~A}$ ). The mean of face rubbing times at the 5 and $10 \mathrm{mg} / \mathrm{kg}$ of LP 211 pretreated groups in Phase I were reduced to $54.6 \pm 2.8$ and $35.3 \pm 2.28$ seconds (both $\mathrm{p}<0.001$, respectively, which were significantly different from the vehicle-treated group (Figure 2B). Similarly, LP 211 at doses of 5 and $10 \mathrm{mg} / \mathrm{kg}$ also significantly decreased face

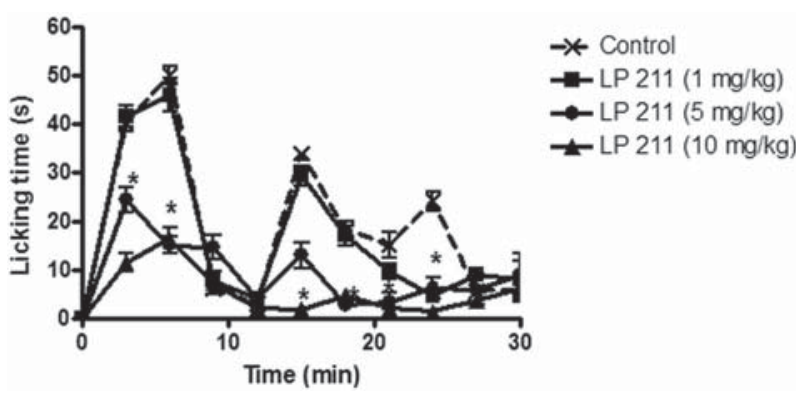

A

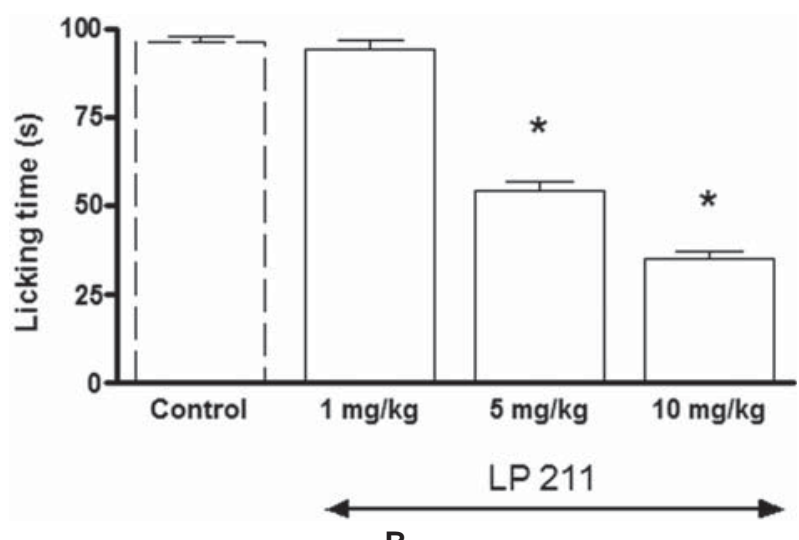

B

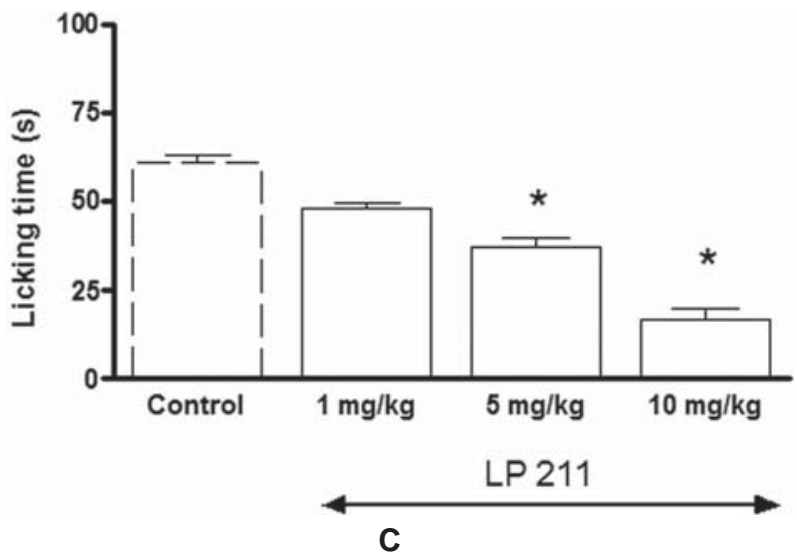

Figure 2- Time course of face rubbing activity induced by formalin injection into upper lip after systemic administration of LP 211, a selective 5-HT7 receptor agonist, or vehicle treatment. Mice were pretreated with systemic administration of LP 211 (1, 5, and $10 \mathrm{mg} / \mathrm{kg}$ ), $30 \mathrm{~min}$ prior to injection of $4 \%$ formalin $(10 \mu \mathrm{l})$ into upper lip (A). Bar graphs represent the mean cumulative face rubbing time in $s$ at Phase I (0-9 min) (B) and Phase II (12-30 min) (C). * $\mathrm{P}<0.05$, differences from vehicle groups (Bonferroni post hoc test) 
rubbing times during Phase II to $37.2 \pm 2.7$ and $17.88 \pm 2.94 \mathrm{~s}$ (both $\mathrm{p}<0.001$ ), respectively, when compared with $5 \%$ DMSO-treated vehicle group (Figure 2C).

\section{DISCUSSION}

In this study, we have demonstrated that selective 5-HT7 receptor agonists elicit analgesic effects on orofacial pain. Our data confirm previous studies implying a role of $5-\mathrm{HT} 7$ receptors in pain pathways.

The pathologic states of the teeth and the related structure induced acute orofacial pain is one of the most common pain, and it is well known that the orofacial region is heavily innervated by the trigeminal nerve. The orofacial formalin test is a recognized model of animal model of nociception related to trigeminal pain ${ }^{13}$. Formalin, as an electrophile irritant, induces tissue injury following its intracutaneous injection accompanied with prototypical a biphasic pattern of pain response ${ }^{6}$. The early phase is generally attributed to a direct effect of formalin on the nociceptors, while the late phase appears to be dependent on an inflammatory reaction in the peripheral tissues and functional changes in spinal and brain stem spinal cord ${ }^{6}$. In the orofacial formalin test, face rubbing with the ipsilateral forepaw due to formalin injection into the upper lip has been mentioned as a specific nociceptive response ${ }^{18}$.

The serotonin in peripheral, spinal and supraspinal sites play in important role in the regulation of pain. Following tissue injury or inflammation, a variety of mediator or modulators together with $5-\mathrm{HT}$ are released that activate or sensitize nociceptors ${ }^{8}$. It has been hypothesized that $5-\mathrm{HT}$, functioning in combination with other inflammatory or algesic mediators significantly modulate pain transmission in peripheral and central nervous system. 5-HT modulates the pain via its receptors. Several different subtypes of 5 -HT receptors have been suggested to be involved in pain transmission and pain modulation ${ }^{19}$. However, the multiplicity of 5-HT receptors and the complex circuitry of pain transmission in peripheral and central nervous system complicates the analysis of subtypes of 5-HT receptors involved in the analgesia.

The 5-HT7 receptor was the lastly identified serotonin receptor subtype. Our previous studies and other studies show that 5-HT7 receptor play a key role both in endogenous pain control and exogenously administered opioid and non-opioid analgesics drug action ${ }^{8,19,21}$. There are very few studies that examine the analgesic effects of selective 5-HT7 receptor agonist. Brenchat, et al.4,5 (2010; 2012) reported that systemic administration of selective 5-HT7 agonists such as E-57431, AS-
19, and E-55888 blocked nerve injury-induced mechanical and thermal hyperalgesia in rat. In inflammatory carrageenan model, Albayrak, et al. ${ }^{1}$ (2013) found that AS-19 elicits anti-inflammatory action with concomitant blockade of the increase in 5 -HT7 receptor expression induced by intrapaw injection of carrageenan.

The important finding of this study is that the intraperitoneal administration of the selective 5-HT7 receptor agonists LP 44 or LP 211 produced an antinociceptive activity in both phases of the orofacial formalin test. This study expands the previous studies indicating the analgesic effects of 5-HT7 receptor agonist in other animal models of pain as to the efficacy of this group of drugs on orofacial pain. In line with previous reports describing anti-inflammatory and analgesic action of 5-HT7 receptor agonists under sensitization painful condition ${ }^{5}$, as expected, we found that LP 44 and LP 211 reduced the nociceptive behavior in both phases of the orofacial formalin test. As CNSpenetrant drugs, after systemic administration, LP 44 and LP 211 can access peripheral, spinal, and supraspinal sites ${ }^{15}$. Thus, in the present study, the site of action underlying analgesic effects of 5-HT7 agonist is unclear. Several studies demonstrated the involvement of descending serotonergic systems in modulating the orofacial nociception? ${ }^{7}$. Interestingly, we reported the special important role of 5-HT7 in the descending pain inhibitory pathways ${ }^{7,21}$. Neuroanatomical studies demonstrate the existence of 5-HT7 receptors in the substantia gelatinosa of the trigeminal subnucleus caudalis, which play a critical role in mediating orofacial nociception. Thus, it is possible to speculate that the antinociceptive action of LP 44 and LP 211 may be attributed to the activation of 5-HT7 receptors in the substantia gelatinosa neurons of the trigeminal nerve. Nevertheless, we cannot exclude the possibility that $5 \mathrm{HT} 2 \mathrm{~A}$ receptors contribute to antinociception in the other brain areas and/or in the periphery. Further studies are needed to clarify the exact mechanism of analgesic action of 5-HT7 receptor agonist on orofacial pain.

\section{CONCLUSION}

In conclusion, our results suggest that targeting 5-HT7 receptor might provide a new therapeutic tool for the treatment of orofacial painful conditions. However, the efficacy of 5-HT7 receptor agonist should be tested in human orofacial pain models. 


\section{REFERENCES}

1- Albayrak A, Halici Z, Cadirci E, Polat B, Karakus E, Bayir Y, et al. Inflammation and peripheral 5-HT7 receptors: the role of 5 -HT7 receptors in carrageenan induced inflammation in rats. Eur J Pharmacol. 2013;715:270-9.

2- Bardin L. The complex role of serotonin and 5-HT receptors in chronic pain. BehavPharmacol. 2011;22:390-404.

3- Benyamin R, Trescot AM, Datta S, Buenaventura R, Adlaka $\mathrm{R}$, Sehgal $\mathrm{N}$, et al. Opioid complications and side effects. Pain Physician. 2008; 11:105-20.

4- Brenchat A, Nadal X, Romero L, Ovalle S, Muro A, SánchezArroyos $\mathrm{R}$, et al. Pharmacological activation of 5 - $\mathrm{HT}$ T receptors reduces nerve injury-induced mechanical and thermal hypersensitivity. Pain. 2010;149:483-94.

5- Brenchat A, Rocasalbas M, Zamanillo D, Hamon M, Vela JM, Romero L. Assessment of 5-HT(7) receptor agonists selectivity using nociceptive and thermoregulation tests in knockout versus wild-type mice. Adv Pharmacol Sci. 2012;2012:312041.

6- Chen Y, Kanju P, Fang Q, Lee SH, Parekh PK, Lee W, et al. TRPV4 is necessary for trigeminal irritant pain and functions as a cellular formalin receptor. Pain. 2014;155:2662-72.

7- Dogrul A, Seyrek M. Systemic morphine produce antinociception mediated by spinal 5-HT7, but not 5-HT1A and 5-HT2 receptors in the spinal cord. Br J Pharmacol. 2006;149:498-505.

8- Dogrul A, Seyrek M, Akgul EO, Cayci T, Kahraman S, Bolay H. Systemic paracetamol-induced analgesic and antihyperalgesic effects through activation of descending serotonergic pathways involving spinal 5- $\mathrm{HT}_{7}$ receptors. Eur J Pharmacol. 2012;677:93101.

9- Godínez-Chaparro B, Barragán-Iglesias P, Castañeda-Corral G, Rocha-González HI, Granados-Soto V. Role of peripheral $5-\mathrm{HT}(4), 5-\mathrm{HT}(6)$, and 5-HT(7) receptors in development and maintenance of secondary mechanical allodynia and hyperalgesia. Pain. 2011;152:687-97.

10- Hargreaves K, Abbott PV. Drugs for pain management in dentistry. Aust Dent J. 2005;50:S14-22
11- Luccarini P, Childeric A, Gaydier AM, Voisin D, Dallel R. The orofacial formalin test in the mouse: a behavioral model for studying physiology and modulation of trigeminal nociception. J Pain. 2006; 7:908-14.

12- Mehlisch DR. The efficacy of combination analgesic therapy in relieving dental pain. J Am Dent Assoc. 2002;133:861-71.

13- Miranda HF, Noriega V, Zepeda RJ, Sierralta F, Prieto JC. Synergism between fentanyl and tramadol in tonic inflammatory pain: the orofacial formalin test. Inflammation. 2012;35:1132-7. 14- Nakajima K, Obata H, Ito N, Goto F, Saito S. The nociceptive mechanism of 5-hydroxytryptamine released into the peripheral tissue in acute inflammatory pain in rats. Eur J Pain. 2009;13:4417.

15- Okamoto K, Imbe H, Kimura A, Donishi T, Tamai $Y$, Senba E. Activation of central $5 \mathrm{HT} 2 \mathrm{~A}$ receptors reduces the craniofacial nociception of rats. Neuroscience. 2007;147:1090-102.

16- Rocha-González HI, Meneses A, Carlton SM, Granados-Soto V. Pronociceptive role of peripheral and spinal 5-HT7 receptors in the formalin test. Pain. 2005;117:182-92.

17- Russell R. Non-steroidal anti-inflammatory drugs and gastrointestinal damage - problems and solutions. Postgrad Med J. $2001 ; 77: 82-8$.

18- Tamaddonfard E, Erfanparast A, Farshid AA, Khalilzadeh $E$. Interaction between histamine and morphine at the level of the hippocampus in the formalin-induced orofacial pain in rats. Pharmacol Rep. 2011;63:423-32.

19- Viguier F, Michot B, Hamon M, Bourgoin S. Multiple roles of serotonin in pain control mechanisms - implications of 5-HT7 and other 5-HT receptor types. Eur J Pharmacol. 2013;716:8-16. 20- Yang EJ, Han SK, Park SJ. Functional expression of 5-HT7 receptor on the substantia gelatinosa neurons of the trigeminal subnucleus caudalis in mice. Brain Res. 2014;16:73-82.

21- Yesilyurt O, Seyrek M, Tasdemir S, Kahraman S, Deveci MS,

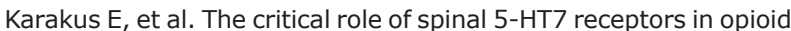
and non-opioid type stress-induced analgesia. Eur J Pharmacol. 2015;762:402-10. 